Published in Adaptive Behaviour: doi.org/10.1177/1059712318770387

Please quote from the published version.

\title{
Going Wide: Extended Mind and Wittgenstein
}

Victor Loughlin

Centre for Philosophical Psychology

University of Antwerp

Belgium

victorloughlin@hotmail.co.uk

\begin{abstract}
Extended mind remains a provocative approach to cognition and mentality. However, both those for and against this approach have tacitly accepted that cognition or mentality can be understood in terms of those sub personal processes ongoing during some task. I label this a process view of cognition (PV). Using Wittgenstein's philosophical approach, I argue that proponents of extended mind should reject PV and instead endorse a 'wide view' of mentality. This wide view clarifies why the hypothesis of extended mind (HEM) is incoherent. However, this view also indicates why the hypothesis of extended cognition (HEC) could be true.
\end{abstract}




\section{Introduction}

Extended mind, broadly understood, is the claim that during certain tasks, our dependence upon environmental objects can be such that those objects can literally become part of the processes and states that realize our cognizing. Think of someone whose reliance on their Smartphone is such that they hardly do anything without it. This Smartphone could be more than simply a tool. Given the right conditions, it could instead be viewed as a genuine part of that person's mind. Or so claim proponents of extended mind (Clark and Chalmers, 1998).

It is now standard to read the extended mind claim (henceforth EM) as a metaphysical claim. Read as a metaphysical claim, for EM to be true, environmental objects or processes must play a constitutive (and not merely causal) role in realizing our capacities to think or remember. To borrow Clark and Chalmers' famous example of Otto and his notebook, their claim isn't simply that the markings in Otto's notebook cause Otto's dispositional belief. Rather their claim is that such markings are part of those material processes that constitute or realize Otto's belief (ibid).

There are also grounds to think that EM should be read as a metaphysical claim. First, doing so distinguishes EM from its near conceptual rival, the Hypothesis of Embedded Cognition or HEMC (Rupert, 2004). HEMC is the claim that while environmental objects or processes may be essential to the exercise of some cognitive or mental capacity e.g., Otto's remembering may be facilitated by his accessing his notebook, it does not follow that such objects or processes are thereby part of the processes that constitute that capacity. That is, HEMC denies the metaphysical implications of EM. Hence, understanding EM as a metaphysical claim helps locate it in terms of an alternative view like HEMC.

Second, attempts to view EM as only an explanatory endeavour confront the difficulty that it is unclear that EM has any explanatory edge over HEMC (see Rupert, 2004; also Sprevak, 2010). In which case, going explanatory about EM invites the danger of a stalemate between opponents and proponents of EM. By contrast, viewing EM as a 
metaphysical claim has the merit of clarifying how the claim could be either confirmed or denied. For example, if the constituents of cognition or mentality do in fact extend to include environmental objects and processes, then EM could be true. Alternatively, if such constituents remain inside the skull, then EM could be false. For these reasons, I will read EM as a metaphysical claim.

Interestingly, both those for and against EM can be understood as tacitly accepting what I will call a process view of cognition (PV). The central contention of $\mathrm{PV}$ is that constitutive questions about cognition or mentality, that is, questions about what cognition or mentality is, can be answered by identifying accompanying processes, where the term 'accompanying processes' refers to those sub-personal spatial and temporal processes ongoing during some task.

PV has taken different forms in this debate. But the motivation for accepting PV in the context of extended mind seems straightforward. Consider that whenever you or I think or remember, it can seem natural to speculate that there must be some process occurring now that makes our activity one of thinking or remembering. We can then wonder as to the extent of that process. Does this process remain confined to the head? If so, then EM is false. Alternatively, does this process also extend to include environmental objects? If so, then EM is true.

However, drawing upon Wittgensteinian considerations, I will argue that proponents of EM should in fact reject PV and embrace what I (and others) have labeled a wide view of mentality (Loughlin and Zahidi, 2017).

For example, later Wittgenstein (2001) explored in detail the tendency we have to appeal to accompanying processes to understand mentality (all subsequent references will be to the later Wittgenstein). ${ }^{1}$ Wittgenstein challenged this tendency by reminding us of the non-mediative link between our use of psychological concepts and our behaviours. This link ensures that our cognitive or mental capacities are

\footnotetext{
1 As pointed out by Noë (2004, p220), there is reason to think Wittgenstein might have been sympathetic to extended mind. Wittgenstein wrote: "I really do think with my pen, for my head often knows nothing of what my hand is writing" (1998, p24e).
} 
manifested or displayed in what we say and do. That is, it is the norm governed practices and contexts within which we say someone is thinking or remembering that makes an agent's activity one of thinking or remembering. This clarifies why PV is false. PV is false because there is nothing ongoing, say, at the moment I am thinking or remembering, that makes my activity one of thinking or remembering. I shall propose that proponents of EM thus use these Wittgensteinian considerations to reject PV and adopt instead a wide view, according to which a given activity is cognitive or mental if and/or when it accords with wider behavioural conditions i.e., the conditions found in norm governed practices and contexts.

This proposal impacts on the debate over extended mind in the following way. On the one hand, rejecting PV and going wide clarifies that cognition or mentality should not be understood as some bounded entity that can extend into the environment. In other words, the hypothesis of extended mind (HEM), that is, the standard reading of extended mind given in Clark and Chalmers (1998), can be discarded as incoherent. On the other hand, this clears the way to investigate those causal mechanisms that underpin our various cognitive or mental capacities. If such mechanisms can be shown to extend to include environmental objects or processes, then the hypothesis of extended cognition (HEC) could be true. Thus, rejecting PV and going wide could be attractive strategy for those keen to discard HEM and develop HEC.

The layout of the paper then is as follows. In section 'A Process View of Cognition', I detail how both opponents and proponents of EM can be understood as offering views that are compatible with PV. In section 'Wittgenstein', I describe how Wittgensteinian considerations clarify why PV is false. In section 'Going wide', I propose that proponents of EM should reject PV and adopt instead a wide view.

\section{A Process View of Cognition (PV)}

Clark and Chalmers (1998) originally launched extended mind in terms of cognitive processes and cognitive (or mental) states. Other participants in this debate have since accepted that constitutive questions about cognition or mentality, that is, questions about what cognition or mentality is, can be answered by identifying accompanying processes. Here the term 'accompanying processes' refers to those sub-personal 
spatial and temporal processes ongoing during some task. I call this a Process View of Cognition (PV).

If PV is correct, then there must be a process, either ongoing inside the agent's head or spread out between the agent and their environment, that makes a given task a cognitive one. One way (though not the only way) to flesh this out is to conceive of the process in question as possessing special properties such as those found in a 'mark of the cognitive'. The search for marks of the cognitive has proved a popular strategy in the debate over extended mind. On the one hand, opponents of EM, like Adams and Aizawa (2001, 2010a,b) have appealed to such a mark in order to demonstrate that EM is false. On the other hand, proponents of EM, like Rowlands (2010), have appealed to such a mark in order to demonstrate that EM is true.

Now, while it would be a stretch to categorize these respective marks of the cognitive as simply statements of PV or reducible to PV, they nonetheless are compatible with PV. ${ }^{2}$ I claim this demonstrates how both opponents and proponents of EM have tacitly accepted PV.

For example, Adams and Aizawa (2001, 2010a,b) have claimed that (1) cognition involves representational states with nonderived content and (2) the cognitive is to be distinguished from the non-cognitive by virtue of underlying causal mechanisms (2010b, p9, p58). (1) and (2) lead them to propose the following mark of the cognitive: "cognition is constituted by certain sorts of causal processes that involve nonderived content" (2010a, p. 68).

The notion that mentality involves non-derived content is not unique to Adams and Aizawa. Indeed, as they acknowledge $(2010 \mathrm{~b}, \mathrm{p} 31)$, they take this idea from the naturalized semantics literature (see Adams and Aizawa, 2010b, chapter 3 for a full discussion). Yet what exactly is such content? Non-derived content, say Adams and Aizawa (2010b), refers to the information garnered in an intentional agent's thoughts, experiences and perceptions (ibid, p32). Such content is to be contrasted with bodily

\footnotetext{
2 Other marks of the cognitive are perhaps possible. However, as far as I am aware, no such alternatives are readily available in the literature on extended mind. Indeed, I would venture that the marks provided by Adams and Aizawa and Rowlands remain the leading candidates.
} 
external objects, like traffic lights, gas gauges, and flags, which possess only derived content, that is, informational content derived from other intentional agents (ibid).

Adams and Aizawa argue that cognitive psychological research has revealed that the only causal mechanisms that possess non-derived content are those mechanisms found inside the head. As such, the mechanisms that constitute or realise our cognitive or mental capacities are, for purely contingent reasons, intracranial. Consequently, EM is false. Yet this dismissal of EM, I claim, is compatible with PV. For, as their mark of the cognitive attests, Adams and Aizawa insist that cognition is constituted by those processes ongoing during some task, which, they argue, are those subpersonal causal mechanisms that possess non-derived content.

However, contrary to Adams and Aizawa, Rowlands (2010) has sought to demonstrate that EM is true. For Rowlands, "processes of manipulation and transformation of [bodily] external structures should be regarded as cognitive and not as merely extraneous causal accompaniments to the supposedly real, internal processes of cognition" (ibid, 124, my italics). Such processes are cognitive, claims Rowlands, whenever they fulfill the following four conditions.

The first condition is that a process must involve the manipulation and transformation of information-bearing structures. The second condition is that the manipulation and transformation of such structures must have the proper function of making new information available to the agent or to processing operations within the agent. The third condition is that this new information must be made available to the agent via a representational state with non-derived content. The fourth condition is that the agent must own the process (ibid, p110-111).

Note that one could read this as not compatible with PV. After all, if what matters are processes of manipulation and transformation that make new information available to the agent and the agent owns such processes, then such processes could be pitched at the personal and not sub-personal level. However, a closer inspection of Rowlands' mark reveals that there is such a compatibility. 
For example, as part of the fourth condition of his mark, Rowlands uses his analysis of intentionality to detail how personal-level processes can be owned. ${ }^{3}$ Rowlands argues that on the standard model of intentionality, there is an ambiguity in the notion of mode of presentation, such that the notion can be interpreted to mean either (1) an empirical mode of presentation or (2) a transcendental mode of presentation (ibid, p185).

The empirical mode of presentation refers to the contents of experience (the shininess and redness of a tomato, for example). The transcendental mode of presentation, on the other hand, refers to those conditions that make possible, or in virtue of which, the object (such as the tomato) is presented to our awareness as being the way it is. In other words, the transcendental mode of presentation is that "in virtue of which the tomato, or relevant part of the world, is disclosed or revealed to me as shiny and red. The non-eliminable core of intentional experience, therefore, consists in a disclosure or revelation of the world" (ibid, p186, emphasis in original).

According to Rowlands, "the relevant sort of disclosure will be that belonging to the vehicles of cognition rather than the content of cognitive states" (ibid, p195). Such "causal disclosure" (ibid), says Rowlands, is not restricted to brain states but rather can extend to include saccadic eye movements, probing and exploratory activities in the identification of sensorimotor contingencies, and the manipulation and exploitation of the optic array (ibid, p202). Indeed, when such processes are operating as "vehicles of disclosure" (ibid), then they are part of the conditions that disclose or reveal the world to the agent, that is, they are the processes with or in virtue of which the agent becomes aware of their surroundings (ibid). Such processes are sub-personal processes. This suggests that Rowlands' mark is in fact compatible with PV. For among the conditions that make a process cognitive, claims Rowlands, are those processes that disclose or reveal the world to the agent, which include (though are not limited to) ongoing sub personal processes, like visual saccades. ${ }^{4}$

\footnotetext{
${ }^{3}$ The following is based on Loughlin (2013).

${ }^{4}$ In the text, I only focus on one source for Rowlands e.g., Rowlands, 2010. In other work, Rowlands (2006) has explored in detail how bodily movements can be representational (see Gallagher, 2017 for analysis). I have restricted my focus in the aforementioned way because my aim here is only to demonstrate that Rowlands' mark of the cognitive, like that of Adams and Aizawa, is compatible with PV. As I make clear in the text, I think this can be done by examining his 2010 work.
} 
It is also worth pointing out that compatibility with PV is not confined to those in search of a mark of the cognitive. Functionalism, as is well known, has played a key role in the debate over extended mind. One of the leading advocates of an "extended functionalist" approach has been Clark (2010). Briefly, Clark views EM as a claim about the constitutive (and not cognitive) role played by an environmental object. Constitution, says Clark, is determined by the information-processing role of that object i.e. its functional role, which is in turn determined by the "precise nature of the coupling" (ibid, p90) that occurs whenever the agent interacts with such an object. This sketch reveals that extended functionalism is compatible with PV. A cognitive activity is constituted by accompanying processes, which are those sub-personal causal couplings that occur whenever an agent interacts with an environmental object. 5

If the foregoing is correct, then both opponents of EM, like Adams and Aizawa, and proponents of EM, like Rowlands and Clark, develop views that are compatible with PV. At the very least, this tacit acceptance of PV by both opponents and proponents of EM suggests that PV cannot help resolve the extended mind debate. This should, I think, motivate a questioning of the merit of PV. In the next section, I will develop this point by arguing that Wittgensteinian considerations can be used to clarify why $\mathrm{PV}$ is in fact false.

\section{Wittgenstein}

\footnotetext{
5 Jumping ahead, the sort of wide view I defend in section 4 of this paper can be viewed as offering the following response to the functionalist (extended or otherwise). Functionalism can be read as the claim that, "what makes something a mental state of a particular type does not depend on its internal constitution, but rather on the way it functions, or the role it plays, in the system in which it is a part" (Levin, 2008). A wide view insists that a given activity is cognitive or mental if and/or when it accords with wider behavioural conditions i.e., the conditions found in norm governed practices and contexts. But if so, then, pace the functionalist, it is not the sub personal role (function) a state plays within some system that makes that state mental. States (or activities) are mental dependent upon on whether or not they satisfy wider behavioural conditions. Functionalism is thus false. On the other hand, if functionalism were instead read as identifying the role (function) of states within some system pitched at the sub-personal level, then this would be compatible with a wide view. For, as I make clear with the Smartphone example (see section 4), going wide about mentality is compatible with there being subpersonal systems, as could occur when an agent is causally coupled to an environmental object.
} 
In the introduction, I claimed that a possible motivation for accepting PV in the context of extended mind is our tendency to speculate that, whenever you or I think or remember, there must be some process occurring now that makes our activity one of thinking or remembering.

I claim such a tendency is evidence that we are, in Wittgenstein's words, 'captivated by a picture' (2001, s115). By employing Wittgenstein's philosophical approach, that is, by assembling reminders about how we actually use psychological concepts, we can cease to be so captivated. This is because such reminders can help clarify for us why PV is false. ${ }^{6}$

Suppose, for example, I watch someone building a wall. While they do so, I notice that they seem to carefully weigh certain bricks in their hands before setting them on the wall, sometimes discarding one, sometimes picking up another. Done in such a way, we would probably call the actions of the builder "thoughtful". For although the builder has not said anything, there nonetheless seems to be something considered or reflective about what they are doing.

According to Wittgenstein, this may lead us to picture thinking as involving some "process, which may accompany something else or can go on by itself" (ibid, s330). For instance, in calling what the builder is doing "thoughtful", we seem to be identifying some process ongoing inside the builder. Yet how do we identify this process?

Continuing our example, suppose I were to stop the builder and ask him to explain to me his actions. It would be odd if he could not furnish me with reasons for what he is doing. However, the reasons the builder gives cannot be the process we are searching

\footnotetext{
${ }^{6}$ In this paper, I will not examine the many interpretative issues Wittgenstein's later work raises. However, I will say the following. Stern (2006) divides interpreters of later Wittgenstein into two broad camps. On the one hand, there are those who regard Wittgenstein as someone profoundly skeptical about the remit of philosophy ('pyrrhonian' interpreters). On the other hand, there are those who insist that, while Wittgenstein's approach has distinctively therapeutic elements, the outcome of this therapy can nonetheless be a positive one ('non-pyrrhonian' interpreters). One way to understand this could be to say that, by clarifying how our language-games operate in our form of life, we can gain new insight into the issues that trouble us. If so, then my use of Wittgenstein's philosophical approach is non-pyrrhonian, since I am using his approach to gain new insight, such as indicating why PV is false.
} 
for. For, in contrast to processes, we don't usually take reasons to have properties like duration, that is, beginnings, middles and endings. As such, whatever else reasons are, they are not processes. ${ }^{7}$

Yet if the builder cannot identify the process we are looking for, then how can we? For why would we be in a better position than the builder to identify what he is thinking? In other words, if we insist on picturing thinking as a process going on inside the builder, then it is not clear how either the builder or ourselves could identify this process. ${ }^{8}$

Why does this problem arise? Wittgenstein offers the following diagnosis:

"The first step is the one that altogether escapes notice. We talk of processes and states, and leave their nature undecided. But that's just what commits us to a particular way of looking at the matter. For we have a definite concept of what it means to learn to know a process better. (The decisive move in the conjuring trick has been made, and it was the very one that seemed to us quite innocent.)" (ibid, s308, my italics).

In other words, our problem, insists Wittgenstein, arises from our uncritical acceptance of the aforementioned picture. We dissolve our problem by rejecting that picture. And we do this by instead asking ourselves: what are the particular circumstances that fix our use of the concept 'thinking' (ibid, s154, s155)?

\footnotetext{
${ }^{7}$ One way to expand on this point would be to say that giving reasons is something one is able to do. And understood as a capacity, giving reasons is not a process, even in cases where giving reasons could have process-like characteristics e.g. when I describe to someone the steps I took to calculate some mathematical sum. Here we can draw a parallel with what Wittgenstein says about understanding: "In the sense in which there are processes (including mental processes) which are characteristic of understanding, understanding is not a mental process" (2001, s154). Arguably the same holds true for giving reasons.

${ }^{8}$ Notice that the problem here is conceptual, not empirical. Suppose, for example, we opened up the builder's head and were able to identify some mechanism occurring inside his brain. Why should this mechanism (or any mechanism like it) be the process we are searching for? The builder cannot answer our question. He can give us reasons for his actions but he cannot identify the process we are looking for. And we can't answer this question. For why would we be in a better position than the builder to determine what he is thinking? As Wittgenstein says, we are in a 'muddle' (2001, s153).
} 
For example, in the case of the builder, what does it mean to call his actions "thoughtful"? One possibility is that we are characterizing the builder's behaviour as being of a certain sort, that is, as being such that if, say, I were to stop him and ask him to explain to me what he is doing, he could give me reasons for his actions. It is thus the builder's capacity to give reasons that justifies my characterization of his actions as "thoughtful". This reminds us that it is internal to our use of a psychological concept, like 'thinking', that such use is confirmed by the satisfaction of certain conditions, like being able to give reasons (Glock, 1996).

Notice that the term 'internal' should not be confused with some process inside the head. Rather it is a reminder that there is a non-mediative link between our use of a psychological concept, like 'thinking', and our behaviour, which ensures that our cognitive or mental capacities are manifested or displayed in what we say and do. Notice also that the term 'psychological concepts' should not be confused with interior mental items. As talk of a non-mediative link clarifies, concepts can be understood to be doings or behaviours e.g., we call the actions of the builder "thoughtful".

Internal relations "depend on how we describe things" (ibid, p327). That is, it is the norm governed practices and contexts within which we describe someone as thinking or remembering that ensures an agent's activity is one of thinking or remembering. This may appear as if it is simply a matter of convention as to what activities we call "thinking" or "remembering". Yet while there is a difference between our use of psychological concepts and behaviour, there is "no gap to be bridged" (ibid), since if different behavioural conditions were appealed to, then this would no longer be thinking or remembering as we understand these capacities. In other words, it is not just a matter of convention. It is instead built into the very games we play with language that we call some activities and not others "thinking" or remembering". Indeed, to do otherwise would be to occupy a different form of life.

This impacts on PV in the following way. If it is wider behavioural conditions i.e., the conditions found in norm governed practices and contexts, that determine if and/or when an activity is an example of a cognitive or mental capacity, then it follows that there is nothing ongoing, say, at the moment I am thinking or remembering, that 
makes my activity one of thinking or remembering. Instead, it is "what leads to, surrounds, and follows from the..movements with which we usually associate the activity [that make that activity cognitive or mental]" (Klagge, 1995, p473). This clarifies why PV is false. PV is false because thinking or remembering are not constituted by any sub-personal processes ongoing at the moment you or I think or remember.

This isn't to deny that what you or I do at any moment matters. This also isn't to deny that there are ongoing sub-personal processes. Rather it reminds us that, when it comes to thinking or remembering, what we do at any moment matters only to the extent that what we are doing now can be understood as satisfying wider behavioural conditions. And no sub-personal process (ongoing or otherwise) can satisfy such conditions. ${ }^{9}$

Now, for those opposed to EM, like Adams and Aizawa, these sorts of Wittgensteininan considerations may look unpersuasive. Indeed, they may object that cognitive science is often understood as aiming to upset or challenge folk psychological notions. Hence, if Wittgensteinian considerations simply involve an appeal to such notions, then using his approach to challenge cognitive science begs the question against such a science. For it would seem to take as given that folk psychological notions must trump the explanatory concerns of scientists.

However, while Wittgenstein's approach does indeed appeal to our everyday use of psychological concepts, the aim, as I have made clear, is not to settle accounts about what can and cannot be said about some concept. It is rather to liberate us from captivating pictures. Assuming that there is some sub-personal process occurring now that makes a given activity a cognitive or mental one is such a picture. We cease to be

\footnotetext{
${ }^{9}$ Wittgenstein could be read as denying that there must be an a priori connection between mental explanations and explanations pitched at sub-personal levels. For example, Thornton (2015) takes Wittgenstein to be "caution[ing] against assuming that a pattern at one level [say, the mental or psychological level] must be relatable to a pattern at a lower level [say, the sub-personal level]" (p7). Given that PV is built on the tendency to think that there must be such a connection, as I have claimed, then this supports using Wittgenstein to clarify why PV is false. However, Thornton also points out that Wittgenstein does not exclude the possibility of establishing "local connections", that is, a posterioi connections, between these levels. In the current context, HEC could be understood as investigating such local connections (see section 4 of this paper).
} 
captivated by that picture once we have clarified why PV is false. Thus, I would argue that we can employ Wittgenstein's philosophical approach, not in order to trump folk psychological notions, but rather in order to (hopefully) dispel conceptual confusion among cognitive scientists (like that generated by tacitly accepting PV) and so help do such a science better. For example, this use of Wittgenstein can help demarcate broader philosophical concerns about what cognition or mentality is from narrower empirical questions about the role of causal mechanisms (see section 4 for development of this point). ${ }^{10}$

Importantly, this use of Wittgenstein's approach should be attractive to those keen on EM, like Rowlands or Clark. For this outcome vindicates their views vis-à-vis the claim that what constitutes our cognitive or mental capacities cannot be solely determined by whatever is ongoing inside our heads. In what follows, I will aim to convince those keen on EM to thus reject PV.

\section{Going wide}

Drawing on Wittgenstein's philosophical approach, I think proponents of EM should reject PV and instead embrace what can be called a wide view of mentality (Loughlin and Zahidi, 2017).

This wide view argues that what makes a given activity cognitive or mental is not where such an activity takes place (either inside and/or outside the head) but rather whether or not it satisfies wider behavioural conditions, like those found in norm governed practices and contexts. A wide view thus rejects the idea, exemplified in $\mathrm{PV}$, that constitutive questions about cognition or mentality can answered by identifying sub-personal accompanying processes and instead emphasizes the role played by wider conditions in constituting our cognitive or mental capacities. The question then is: what consequences does this wide view have for the debate over extended mind?

\footnotetext{
10 The way I have used Wittgenstein's philosophical approach in the text is compatible with the position defended by Hutto and Satne (2018), who claim that philosophical clarification, inspired by Wittgenstein's relaxed view of naturalism, can have scientific benefits.
} 
In order to answer this question, I will introduce a distinction that has recently gained traction within the literature. It is the distinction between, on the one hand, the hypothesis of extended mind (HEM), and on the other, the hypothesis of extended cognition (HEC) (Palmeros, 2014; Pöyhönen, 2014; Bernecker, 2014).

This distinction is not hard and fast. Nonetheless, one way to parse it out is to say that HEC theorists take as given what cognition or mentality is and then seek to identify, for explanatory purposes, the boundaries of those sub-personal processes that underpin a cognitive or mental capacity. Put another way, HEC theorists aim to show that giving an explanation of the sub-personal mechanisms that underpin a cognitive or mental capacity requires appealing to bodily external objects or processes.

By contrast, HEM theorists focus instead on ontological issues, such as those concerning the location of mentality. Understood in this way, HEM can be read as the standard way to formulate EM (see the introduction to this paper). Indeed, as both Palmeros (2014) and Pöyhönen (2014) point out, Clark and Chalmers' example of Otto and his notebook is a case study for HEM, since the example, if plausible, is intended to undermine the intuition that mentality must be solely located within the skull.

Rejecting PV and embracing a wide view demonstrates why HEM no longer makes sense. If our cognitive or mental capacities are determined by our satisfying wider behavioural conditions, then while such capacities obviously have locations (in the trivial sense that everything occurs somewhere), it does not follow that such capacities also have boundaries and so can extend into the environment. HEM, in other words, is incoherent. ${ }^{11}$

\footnotetext{
11 As I outlined in the introduction, embedded mind theorists, like Rupert, are usually understood as challenging the metaphysical implications of EM. Such theorists insist that there is only a causal (and not constitutive) dependence between an agent and an environmental object during a task or activity. Given that rejecting PV and embracing a wide view renders HEM (the hypothesis of extended mind) incoherent, then this could be taken to support an embedded position. However, notice that Rupert (2010) views cognition in terms of underlying physical mechanisms "each element of which contributes, as a member of overlapping subsets of mechanisms, to a wide range of cognitive outcomes" (p12). This seems to accept that constitutive questions about what mentality is can be answered by identifying accompanying processes, where such processes are those sub-personal processes ongoing during a task. In other words, this accepts PV. But if so, then rejecting PV would also entail rejecting embedded mind.
} 
On the other hand, rejecting PV and embracing a wide view can potentially support HEC. For there still remain questions to be asked about those causal mechanisms that underpin a given cognitive or mental capacity. Causal mechanisms obviously have identifiable spatial and temporal boundaries. Hence, proponents of HEC can seek to determine if the mechanisms that underpin a given capacity can extend to include non-bodily processes and/or environmental objects. If they do, then HEC could be true.

By way of illustration, recall the example given earlier of someone who makes extensive use of his or her Smartphone. Suppose this individual is now typing on their phone to a friend. They may be typing for a particular reason e.g., to tell their friend about an embarrassing moment that occurred at work today. They may be anxious for their friend to respond in a particular way (with sympathy, not with derision), so they are choosing their words carefully or perhaps peppering their text with emoticons. Most people would agree, I think, that this activity qualifies as a cognitive or mental one. Yet what is it about this activity that makes it cognitive or mental?

According to a wide view, the individual's typing on their Smartphone qualifies as cognitive or mental because it satisfies wider behavioural conditions. For example, if I were to stop the individual while they were typing and ask them what they were typing or who they were sending their message to, then they could answer my questions in a straightforward fashion. As with the case of the builder (see section 3), it is the Smartphone user's satisfaction of those conditions found in norm governed practices and contexts that leads me to describe what they are doing as an example of thinking.

Notice a number of things about this example. First, if this example is correct, then $\mathrm{PV}$ is false. There are no sub-personal processes ongoing while the individual is typing on their Smartphone that makes what the individual is doing a cognitive or mental activity. Second, this example does not support HEM. It is the individual's capacity to satisfy wider behavioural conditions that matters and this capacity is not some bounded entity that extends into the environment. Third, this example is 
compatible with asking questions about the extent of sub-personal processes. That is, this example is compatible with HEC being true.

For instance, various neural processes obviously need to be operational inside the individual's head for them to be able to type on their phone. Moreover, there could also be a close causal coupling occurring whenever the individual uses their phone. Clark describes the coupling of interest to (some though by no means all) proponents of EM as involving "continuous reciprocal causation" or CRC (Clark, 1997, p163; see also Clark and Chalmers, 1998). CRC occurs when "some system $\mathrm{S}$ is both continuously affecting and simultaneously being affected by, activity in some other system O" (Clark, 2008, p24). That is, when the back-and-forth between an individual and an environmental object involves $\mathrm{CRC}$, then just as the agent causes changes in that object through their interaction with it, then similarly the object can cause changes in the agent through that interaction as well. Under these circumstances, the agent and object could form one extended system.

This could be what is happening in the Smartphone example. The coupling between the individual and their Smartphone could such that this coupled agent-object system is part of the mechanisms that underpin the agent's capacity to think. If so, then giving an explanatory account of the sub-personal mechanisms that underpin the individual's capacity to think will require including this coupled agent-object system. Thus, the hypothesis of extended cognition, that is, HEC, could be true. And this would be compatible with embracing a wide view. For the agent's activity counts as an example of thinking because it satisfies wider behavioural conditions.

Now consider a different example. Most people would agree that memory is about the recall of information. ${ }^{12}$ If I remember what I did yesterday morning (I took my wife to a doctor's appointment, for example), I am recalling information about what I did yesterday. The standard move (a move evident in the debate over extended mind) is to link recall with retrieval. So when I recall what I did yesterday morning, this means that I retrieved information about what I did yesterday morning. Once recall and retrieval are linked, then it follows that the information I retrieved must have been

\footnotetext{
12 The following is based on Loughlin and Zahidi (2017).
} 
stored somewhere (I can't retrieve something if it isn't stored). Further, once it is accepted that information must be stored somewhere, then there must be a repository for this stored information. For internalists, like Adams and Aizawa, this repository is the brain. For externalists, like Clark and Chalmers, this repository can be spread out between brain, body and world, as in their example of Otto and his notebook. Hence, as Loughlin and Zahidi (2017) point out, both internalists and externalists endorse the memory-as-information-retrieval view.

However, it is possible to accept that memory involves the recall of information without also accepting that this involves information retrieval. Consider the following.

Suppose you asked me to remember the time of our friend's party tomorrow so we know when to leave the house. However, when we subsequently arrive at the party the next day, we find the party is already over. You understandably get very angry. You ask me: "why didn't you remember the right time?"

If the memory-as-information-retrieval view is correct, then I either noted (stored) the correct time of our friend's party or I did not. I obviously did not, hence why we arrive only to find the party already over. However, according to a wide view, for the recall of information to count as an act of remembering, the recalled information has to be appropriated situated and contextualised within the personal and impersonal circumstances of the person. For example, if you hadn't asked me to remember the time, then you couldn't justifiably get angry when we arrived late. As such, it is your asking me to remember the time and my failure to fulfil this order that leads us to call what I did "misremembering". If this is correct, then while remembering involves the recall of information i.e., information that is appropriately situated and contextualised, this need not entail that it also involves the retrieval of something previously stored. It instead means that we satisfy (or fail to satisfy, as in this example) wider behavioural conditions. Thus, adopting such a wide view clarifies that memory does not involve information retrieval.

More could be said here (see Loughlin and Zahidi, 2017 for a fuller account). Nonetheless, notice two things. First, if this wide view is correct, then PV is false. 
There are no ongoing sub-personal processes that make an activity one of remembering or misremembering. Second, questions can still be asked about those causal mechanisms that underpin any act of remembering or misremembering.

For instance, empirical investigation may reveal that the causal mechanisms involved are entirely confined to the brain (the hippocampus of the medial temporal lobe could be such a mechanism, for example). However, investigation may instead reveal that such mechanisms can also sometimes extend to include what you or I do and/or how we use environmental objects. Indeed, there could be circumstances where the keeping of a diary or notebook could be such that, during those moments when the agent is using the diary or notebook, such use is part of the mechanisms that underpin their capacity to remember. That is, giving an explanatory account of the sub-personal mechanisms that underpin the agent's capacity to remember could require appealing to environmental objects. Under these circumstances, the hypothesis of extended cognition or HEC could be true. Nonetheless, the agent's activity counts as one of remembering because it satisfies wider behavioural conditions.

Thus, rejecting PV and embracing a wide view places proponents of HEC in an interesting position. On the one hand, it enables them to demarcate broader philosophical concerns about what cognition or mentality is from narrower empirical questions about the role of causal mechanisms. On the other hand, this ensures that they can follow Ross and Ladymans' advice and insist that, "metaphysical considerations should play no role in deciding how to model cognition... Modelers will and should draw system boundaries in whichever ways maximize efficient capture of local phenomena" (Ross and Ladyman, 2010, p156). ${ }^{13}$ As both the Smartphone and memory examples suggest, doing so raises the possibility that HEC could be true.

\section{Conclusion}

13 Pöyhönen (though for different reasons) seems to reach a similar conclusion: "I contend that choices between externalist and internalist classification strategies are necessarily more local, and based partly on the epistemic aims of the scientific field in question" (Pöyhönen 2014: 755). 
Extended mind remains a provocative claim that arguably still offers a fresh approach to cognition and mentality. However, both those for and against this approach have tacitly accepted that cognition can be understood in terms of sub-personal processes ongoing during some task. I labeled this a process view of cognition (PV). Using Wittgenstein's philosophical approach, I have argued that proponents of extended mind should reject PV and instead embrace a wide view of mentality. Doing so has both negative and positive consequences for the extended mind debate. On the one hand, it demonstrates why the hypothesis of extended mind (HEM) is incoherent. On the other, it highlights how proponents of the hypothesis of extended cognition (HEC) can focus on those causal mechanisms that underpin our mental or cognitive capacities. If explaining such mechanisms requires appealing to environmental objects or processes, then HEC could be true.

\section{Bibliography}

Adams, F, Aizawa, K (2001). The Bounds of Cognition. Philosophical Psychology, 14, pp43-64.

Adams, F, Aizawa, K (2010a). Defending the Bounds of Cognition. In Menary, R (Ed), The Extended Mind (67-80). The MIT Press.

Adams, F, Aizawa, K (2010b). The Bounds of Cognition. Wiley-Blackwell Publishing Ltd.

Bernecker, S. (2014). How to understand the extended mind. Philosophical Issues, 24(1), 1-23. http://doi.org/10.1111/phis.12023.

Clark, A (1997). Being There:Putting the Brain, Body and World Together Again. Cambridge, MA: MIT Press.

Clark, A. \& Chalmers, D. (1998). The extended mind. Analysis, 58, pp. 7-19.

Clark, A (2008). Supersizing the Mind. Oxford: Oxford University Press. 
Clark, A (2010). Coupling, Constitution, and the Cognitive Kind: A Reply to Adams and Aizawa. In Menary, R (Ed), The Extended Mind (pp81-99). The MIT Press.

Hutto, D, Satne, G (2018). Wittgenstein's inspiring view of nature: on connecting philosophy and science aright. Philosophical Investigations, DO1: 10.1111/phin.12193

Gallagher, S (2017). Enactivist Interventions: Rethinking The Mind. Oxford University Press.

Glock, H (1996). A Wittgenstein Dictionary. Blackwell Publishers.

Klagge, J, C (1995). An unexplored concept in Wittgenstein. History of Philosophy Quarterly, 12 (4), 469-486.

Levin, J (2008). Functionalism. In E. N. Zalta (Ed), The Stanford Encyclopedia of $\begin{array}{llll}\text { Philosophy. } & \text { Retrieved } & \text { March } & 2013\end{array}$ http://plato.stanford.edu/entries/functionalism.

Loughlin, V (2013). Review of: Mark Rowlands, The New Science of the Mind: From Extended Mind to Embodied Phenomenology. Phenomenology and the Cognitive Sciences, 12 (4), 891-897.

Loughlin, V \& Zahidi, K (2017). What is left of the Active Externalism debate? European Journal of Philosophy, DOI: 10.111/ejop.12249

Noë, A (2004). Action in Perception. The MIT Press.

Palermos, S, O. (2014). Loops, constitution and cognitive extension. Cognitive Systems Research, 27, p. 25-41.

Pöyhönen, S. (2014). Explanatory power of extended cognition. Philosophical Psychology, 27(5), 735-759. 
Ross, D, Ladyman, J. (2010) "The alleged coupling-constitution fallacy and the mature sciences", in: R. Menary (ed.) The Extended Mind, Cambridge (MA): MIT Press, 2010.

Rowlands, M (2006). Body Language: Representation in Action. Cambridge, MA: MIT Press.

Rowlands, M (2010). The New Science of the Mind: From Extended Mind to Embodied Phenomenology. Cambridge, MA: MIT Press.

Rupert, R (2004). Challenges to the hypothesis of extended cognition. Journal of Philosophy, 101, 389-428.

Rupert, R (2010) Systems, functions, and intrinsic natures: On Adams and Aizawa's The Bounds of Cognition. Philosophical Psychology, 23:1, 113123, DOI: $\underline{10.1080 / 09515080903538867}$

Sprevak, M. (2010). Inference to the hypothesis of extended cognition. Studies in History and Philosophy of Science Part A, 41(4), pp. 353-362.

Stern, D (2006). How many Wittgensteins? In A Pichler, S Saatela (eds): Wittgenstein: The Philosopher and his Works (pp205-229). De Gruyter Online.

Thornton, T. (2015). Against Explanatory Minimalism in Psychiatry. Frontiers in Psychiatry: Hypothesis and Theory, doi: 10.3389/fpsyt.2015.00171.

Wittgenstein, L. (1998). Culture and Value. Blackwell Publishing Ltd.

Wittgenstein, L. (2001). Philosophical Investigations ( $3^{\text {rd }}$ ed.). Blackwell Publishers. 